\title{
MicroRNA-25-3p therapy for intervertebral disc degeneration by targeting the IL-1//ZIP8/MTF1 signaling pathway with a novel thermo-responsive vector
}

\author{
Yong Huang ${ }^{1}$, Leizhen Huang ${ }^{1}$, Li Li ${ }^{2}$, Zhishen Ge ${ }^{3}$, Ganjun Feng ${ }^{1}$, Limin Liu ${ }^{1}$, Yueming Song ${ }^{1}$ \\ ${ }^{1}$ Department of Orthopedic Surgery and Orthopedic Research Institute, West China Hospital, Sichuan University, Chengdu, China; ${ }^{2}$ Department of \\ Science and Technology, West China Hospital, Sichuan University, Chengdu, China; ${ }^{3}$ CAS Key Laboratory of Soft Matter Chemistry, Department \\ of Polymer Science and Engineering, University of Science and Technology of China, Hefei, China \\ Contributions: (I) Conception and design: All authors; (II) Administrative support: None; (III) Provision of study materials or patients: None; (IV) \\ Collection and assembly of data: None; (V) Data analysis and interpretation: All authors; (VI) Manuscript writing: All authors; (VII) Final approval of \\ manuscript: All authors. \\ Correspondence to: Limin Liu. Department of Orthopedic Surgery and Orthopedic Research Institute, West China Hospital, Sichuan University, \\ Chengdu, China. Email: liulimin_spine@163.com; Ganjun Feng. Department of Orthopedic Surgery and Orthopedic Research Institute, West China \\ Hospital, Sichuan University, Chengdu, China. Email: gjfenghx@163.com; Zhishen Ge. CAS Key Laboratory of Soft Matter Chemistry, Department \\ of Polymer Science and Engineering, University of Science and Technology of China, Hefei, China. Email: gezs@ustc.edu.cn.
}

Background: MicroRNAs play important roles in intervertebral disc degeneration (IDD). The therapeutic effects of miRNA-25-3p on IDD and underlying mechanism are unclear.

Methods: Normal and degenerated nuclear pulposus (NP) tissue were collected. Primary NP cells were isolated and treated with different concentrations of interleukin-1 $\beta$ (IL-1 $\beta$ ). IL-1 $\beta$ treated NP cells were interfered with miRNA-25-3p. Associated proteins IL-1 $\beta$, ZIP8, MTF1, extracellular matrix (ECM) degrading enzymes MMP3, MMP13, ADAMTS5, ECM proteins type II collagen, aggrecan and MiRNA-25$3 \mathrm{p}$ were detected by western blotting or qRT-PCR method. Dual luciferase reporter assays were performed to determine potential targets MTF1 of miRNA-25-3p. In vitro miRNA-25-3p transfection efficiency of thermos-responsive vector was observed by fluorescence microscopy. Animal studies were conducted to observe the therapeutic effects of miRNA-25-3p mimic delivered by thermo-responsive vector.

Results: Compared with normal NP tissues, IL-1 $\beta$, ZIP8 and MTF1 significantly increased and miRNA$25-3$ p significantly decreased in degenerated tissues. IL-1 $\beta$ promotes the expression of ZIP8 and nuclear translocation of MTF1 in NP cells. Ultimately, it promotes expression of ECM degrading enzymes and inhibits synthesis of ECM protein. MiRNA- 25-3p could inhibit the effects of IL-1 $\beta$ and the expression of ECM degrading enzymes, and recover the expression of ECM protein. Further investigation showed MTF1 was a target protein of miRNA-25-3p. The thermo-responsive vector could effectively deliver miRNA-25$3 p$ into NP cells. Animal studies demonstrated miRNA-25-3p delivered by the thermo-responsive vector can delay progression of IDD

Conclusions: The thermo-responsive vector delivering miRNA-25-3p could delay the progression of IDD by inhibiting IL-1 $\beta$-induced effects, and may be potential therapy for IDD in future.

Keywords: Intervertebral disc degeneration (IDD); miRNA-25-3p; IL-1 $\beta$; MTF1; thermo-responsive vector

Submitted Sep 02, 2020. Accepted for publication Nov 03, 2020.

doi: 10.21037/atm-20-6595

View this article at: http://dx.doi.org/10.21037/atm-20-6595

(c) Annals of Translational Medicine. All rights reserved. 


\section{Introduction}

Low back pain (LBP) is one of the most common clinical disorders worldwide, impairing quality of life in modern society and imposing significant social and economic burden. Approximately $84 \%$ of the world's population suffers from this condition at some point in their lifetime, with approximately $23 \%$ of them progressing to chronic LBP, and $11-12 \%$ resulting in disability $(1,2)$. The etiology of LBP is multifactorial, among which intervertebral disc degeneration (IDD) is the predominant factor. Current non-operative and operative treatments for IDD are limited to symptomatic management, which has low efficacy and a high risk of opioid reliance (3). The degeneration of intervertebral discs is accompanied by increased expression of inflammatory cytokines, enhanced extracellular matrix (ECM) degradation, loss of water content and changes in disc cell phenotype $(4,5)$. The complicated microenvironment remains a significant challenge for developing a disease-modifying drug to reverse degeneration and restore disc function (6). Therefore, unveiling the critical molecular mechanisms underlying IDD is crucial for exploring innovative therapeutic strategies.

The hallmark of IDD is the high level of inflammatory cytokines secreted by disc cells (7). As a major proinflammatory cytokine, interleukin- $1 \beta$ (IL-1 $\beta$ ) is abundantly produced in degenerated disc tissue and cells, and plays a critical role in disc degeneration $(8,9)$. IL- $1 \beta$ regulates the production and activity of matrix catabolic enzymes, such as matrix metalloproteinases (MMPs) and a disintegrin and metalloprotease with thrombospondin motifs (ADAMTSs), which are primary factors that destroy the ECM in discs $(7,10)$. Both MMPs and ADAMTSs are a large family of zinc-dependent metalloproteinases, as zinc acts as an activator or coactivator of these enzymes $(11,12)$. Simultaneously, the level of intracellular zinc can regulate MMP and ADAMTS expression. A previous study in osteoarthritis showed that IL-1 $\beta$ elevated intracellular zinc concentration via upregulation of the zinc transporter ZIP8. Consequently, MTF1, a metal-dependent transcription factor, responded to IL-1 $\beta$-mediated zinc influx via ZIP8 and translocated into the nucleus to promote the expression of a series of matrix degrading enzymes, including MMP3, MMP13, and ADAMTS5, thereby aggregating cartilage destruction (13). However, IL-1 $\beta$-mediated MMP and ADAMTS expression in IDD via the ZIP8/MTF1 pathway has not yet been investigated.

MicroRNAs (miRNAs) are a class of small, non-coding endogenous RNA molecules which regulate their biological function by guiding their target messenger RNAs (mRNAs) to degradation or translational repression (14). Several lines of evidence have confirmed that miRNAs play a role in IDD deterioration through various pathological processes, such as cell apoptosis, ECM disruption, cell proliferation, and inflammatory responses $(15,16)$. MiRNAs may be promising agents for delaying or reversing disc degeneration. A previous miRNA microarray analysis study showed the expression of miRNA-25 significantly decreased in degenerated disc tissue (17). However, the underlying mechanisms have not yet been discussed. As a member of the miRNA-25 family, miRNA-25-3p has been predicted to silence MTF1 protein expression according to the target gene prediction by the miRBase database (http://www.mirbase.org). It has been suggested that miRNA-25-3p might inhibit IL-1 $\beta$-mediated matrix degrading enzyme expression via targeted silencing of MTF1. It was also shown that miRNA-25-3p might be an ideal candidate for IDD treatment, but this requires further substantiation $(15,17)$.

Increasing evidence demonstrates that miRNA-based gene therapy has significant therapeutic potential in various human diseases $(18,19)$. However, miRNAs and their negatively charged mimics cannot cross the cell membrane easily. In addition, 'naked' miRNAs are highly susceptible to degradation in serum (20). Therefore, miRNA-based treatment must rely on vector-mediated delivery. For miRNAs to translate into effective and successful therapeutic agents, suitable carriers must be nonimmunogenic, in a stable physiological condition, and avoid rapid clearance in vivo. Based on our previous work, a novel thermo-responsive vector was formed by mixed cationic block copolymers (MCBC): Poly(ethyleneglycol) (PEG) -b- poly [PAsp(DET)] and poly(Nisopropylacrylamide)block-PAsp(DET) [PNIPAM-b-PAsp(DET)] (Figure 1A). It was demonstrated to be an effective and safe gene vector for gene therapy of IDD by percutaneous injection in a rat model. Heme oxygenase-1 (HO-1) pDNA carried by a thermo-responsive vector has shown high transfection efficiency and stability both in vivo and vitro $(21,22)$. However, the ability of the novel thermo-responsive vector to deliver miRNA-25-3p effectively has not been tested. To further verify the effects of miRNA-25-3p in vivo and to translate this emerging therapy to humans in the future, studies involving preclinical animal models are an essential step. Rat models for disc degeneration induced by puncture have been widely used (23). It provides an effective model 
A

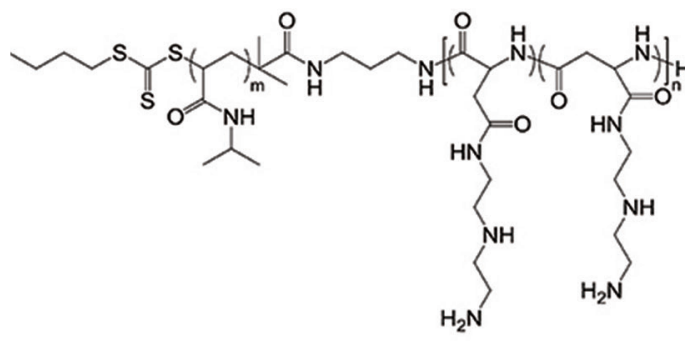

PNIPAM- $b$-PAsp (DET)

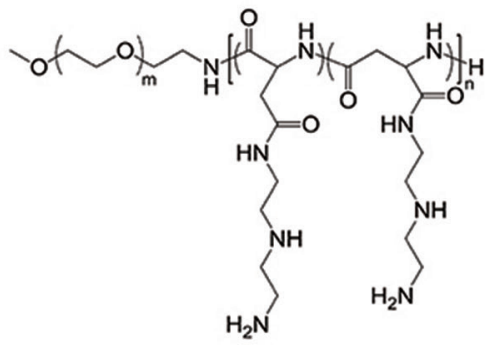

PGE- $b$-PAsp (DET)

B
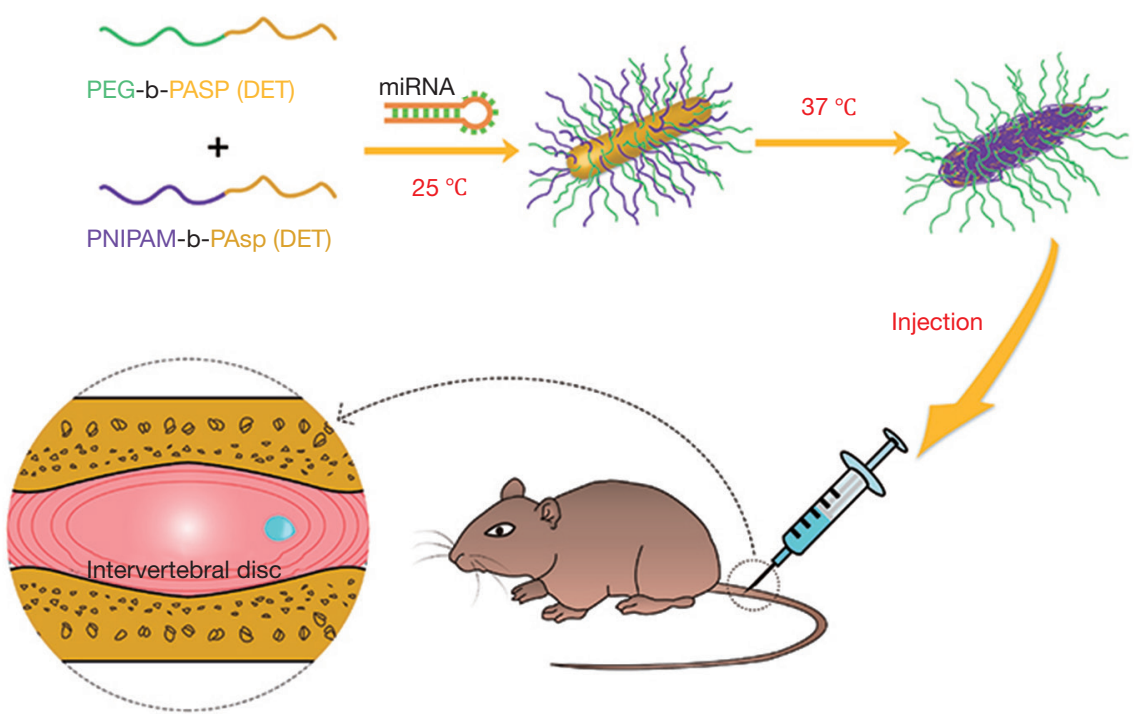

Figure 1 Schematic illustration of miRNA-based gene therapy delivered by a thermo-responsive vector for intervertebral disc degeneration (IDD). (A) The chemical structure of cationic block copolymers: PNIPAM-b-PAsp (DET) and PEG-b-PAsp (DET). (B) The mixed cationic block copolymers (MCBC) PNIPAM-b-PAsp (DET) and PEG-b-PAsp (DET) as vectors for miRNA to form mixed polyplex micelles. With a temperature increase from room temperature $\left(25^{\circ} \mathrm{C}\right)$ to physiological temperature $\left(37^{\circ} \mathrm{C}\right)$, thermo-sensitivity of PNIPAM segments become hydrophobic and form more compact mixed polyplex micelles with hydrophobic and hydrophilic heterogeneous surfaces. The mixed cationic block copolymers delivered miRNA-25-3p for IDD gene therapy.

with easy to implement interventions, minimal risk of damage, and high reproducibility.

Here, we examined the role of the IL-1ß/ZIP8/MTF1 signaling pathway in IDD. Moreover, we investigated the influence of miRNA-25-3p on IL-1 $\beta$ treated nucleus pulposus (NP) cells, and its underlying mechanism. Thereafter, we examined the transfection efficiency of miRNA-25-3p via the thermo-responsive vector. Finally, we established a disc degeneration rat model to investigate the therapeutic effects of miRNA-25-3p delivered by a thermoresponsive vector on IDD (Figure 1B). We present the following article in accordance with the ARRIVE reporting checklist (available at http://dx.doi.org/10.21037/atm-206595).

\section{Methods}

\section{Sample collection}

All procedures performed in this study involving human participants were in accordance with the Declaration of Helsinki (as revised in 2013). Study procedures was approved by the Ethics Review Board of West China Hospital, Sichuan University. Degenerative nucleus pulposus (NP) samples were obtained from patients with IDD. Normal NP samples were obtained from burst fracture patients with spinal cord surgery (Table S1). Written informed consent was obtained from all patients. The degenerative condition of NP samples was evaluated using magnetic resonance imaging (MRI) according to 
Pfirrmann's grading system (24). Samples obtained from burst fracture patients graded as 1 or 2 were classified as the normal control group, and samples graded as 4 or 5 were included in the IDD group.

\section{Isolation and culture of human NP cells}

NP cells were isolated as previously described (25). Normal NP tissues were washed twice in phosphate-buffered saline (PBS) with 1\% penicillin/streptomycin (Invitrogen, Carlsbad, CA, USA), then cut into pieces. The NP cells were released from NP tissues by digestion with $1 \mathrm{mg} / \mathrm{mL}$ type II collagenase (Invitrogen, Carlsbad, CA, USA) for 5 hours at $37^{\circ} \mathrm{C}$. A cell strainer was used to filter the digestive solution. Isolated NP cells were plated and expanded in DMEM containing 10\% fetal bovine serum (FBS) (Gibco, Grand Island, NY, USA) and 1\% penicillin/ streptomycin at $37{ }^{\circ} \mathrm{C}$ in a $5 \% \mathrm{CO}_{2}$ incubator. Culture medium was replaced every 2 days. The second passage cells were used for subsequent experiments.

\section{qRT-PCR}

Total RNA from NP tissue and cells was isolated using TRIzol (Invitrogen, Carlsbad, CA, USA) and the RNeasy Mini Kit (Qiagen, Valencia, CA, USA) according to the manufacturers' protocol. Subsequently, RNA was eluted in $50 \mu \mathrm{L}$ of nuclease-free water, and stored at $-80{ }^{\circ} \mathrm{C}$ for further analysis. After RNA concentration determination using the NanoDrop ND-1000 Spectrophotometer (NanoDrop Technologies, Wilmington, DE, USA), RNA was reverse transcribed with PrimeScript ${ }^{\mathrm{TM}}$ RT Master Mix (TakaRa, Dalian, China) according to manufacturer's instructions. The gene and primer sequences used are shown in Table S2. U6 and $\beta$-actin served as reference genes.

\section{Western blotting}

Western blot analyses were performed according to standard methods. Briefly, proteins were separated on a $10 \%$ SDS-PAGE gel, then transferred to polyvinylidene fluoride (PVDF) membranes (Amersham, Buckinghamshire, UK), which were blocked using $5 \%$ nonfat dried milk for 2 hours. Membranes were incubated overnight at $4{ }^{\circ} \mathrm{C}$ with anti-IL- $1 \beta$ antibody (12703, 1:1,000, CST, USA), antiMTF1 antibody (ab184119, 1:1,000, Abcam, Cambridge, UK), anti-ZIP8 antibody (NBP1-76505, 1:2,000, Novus,
Biologicals, Colorado, USA), anti-MMP3 antibody (NB100-91878, 1:1,000, Novus Biologicals, Colorado, USA), anti-MMP13 antibody (NBP2-45887, 1:1,000, Novus, Biologicals, Colorado, USA), anti-ADAMTS5 antibody (NBP2-15286, 1:1,000, Novus, Biologicals, Colorado,USA), anti- $\beta$-actin antibody (abs118937, 1:3,000, Absin, Shanghai, China), and anti-PCNA antibody (abs13075, 1:2,000, Absin, Shanghai, China). Membranes were subsequently washed with tris-buffered saline and incubated with the secondary antibody for 2 hours at room temperature. Proteins were measured using the enhanced chemiluminescence system.

\section{Immunocytochemistry (ICC)}

Cultured cells were washed 3 times with PBS, fixed with $4 \%$ paraformaldehyde for 20 minutes, permeabilized with $0.25 \%$ Triton $\mathrm{X}-100$ for 5 minutes, and blocked with $5 \%$ bovine serum albumin for 30 minutes. Thereafter, cells were incubated with anti-collagen type II (ab34712, 1:100, Abcam, Cambridge, UK) and anti-aggrecan (ab36861, 1:100, Abcam, Cambridge, UK) at $4{ }^{\circ} \mathrm{C}$ overnight. Cells were washed with PBS and incubated with the secondary antibody IgG-rhodamine (1:200 dilution, Sigma-Aldrich, Deisenhofen, Germany) for 2 hours at room temperature. Nuclei were stained with 4,6-diamidino-2-phenylindole (DAPI; Beyotime, Beijing, China). Fluorescence images were observed and captured under a fluorescence microscope (Zeiss Axioplan microscope, Carl Zeiss Microscopy, Thornwood, NY, USA).

\section{Cell transfection}

The miRNA-25-3p mimics and negative controls (NC) were obtained from GenePharma (Shanghai, China). Human NP cells were transfected using Lipofectamine 2000 (lipo2000) (Invitrogen, Carlsbad, CA, USA) at a concentration of $20 \mathrm{nM}$ according to manufacturer's instructions.

\section{Dual luciferase assays}

The NP cells were co-transfected with $0.4 \mu \mathrm{g}$ of reporter construct, $0.2 \mu \mathrm{g}$ of the pGL-3 control vector, and miRNA-25-3p or NC. Cells were harvested 24 hours posttransfection and assayed using the Dual Luciferase Assay (Promega, Wisconsin-Madison, WI, USA) according to the manufacturer's instructions. 


\section{In vitro miRNA transfection efficiency of MCBC}

NP cells were seeded on a 24-well plate at a density of $2 \times 10^{4}$ cells/well and incubated overnight. At the time of transfection, the medium in each well was replaced with $400 \mu \mathrm{L}$ of DMEM medium. Cy3-miRNA-25-3p/MCBC (5 nmol Cy3- miRNA-25-3p in $20 \mu \mathrm{L}$ solution) at an N/P ratio of 8 were added into each well. This group was named Cy3-miRNA-25-3p/MCBC. For comparison, pure Cy3miRNA-25-3p and Cy3-miRNA-25-3p/Lipofectamine 2000 were also added into the 24 -well plate, separately under the same condition. After a 6-hour incubation, the medium was replaced with fresh normal medium, followed by incubation for an additional 24 hours. Cultured cells were washed 3 times with PBS. DAPI (150 $\mathrm{ng} / \mathrm{mL}$ in PBS) and LysoTracker Green (50 nmol/L) were used to stain nuclei, and later, endo-lysosomes of cultured cells. Cellular uptake was imaged by a fluorescence microscope (Zeiss Axioplan microscope, Carl Zeiss Microscopy, Thornwood, NY, USA).

\section{Animal studies for in vivo miRNA-25-3p therapy}

Animal experiments were performed according to the Guidelines for Animal Experimentation of Sichuan University, and with approval from the Institutional Ethics Committee of West China Hospital, Sichuan University. Three-month-old male Sprague Dawley rats $(250 \pm 20 \mathrm{~g})$ were obtained from the Animal Center in Sichuan University. The animals were anesthetized with isoflurane inhalation. The needle puncture model of IDD was established according to a previous study (26). After determining the location of the intervertebral disc between the fifth to sixth coccygeal vertebrae $\left(\mathrm{Co}_{6-7}\right)$ of each rat via $\mathrm{X}$-ray, a 21-gauge needle was inserted into the center of the NP through the $\mathrm{AF}$ at the $\mathrm{Co}_{6-7}$ level, rotated $180^{\circ}$, and held for 5 seconds. Eighteen model rats were randomly allocated into 3 groups and treated with equal amounts $(10 \mu \mathrm{L})$ of normal saline, including sham $(\mathrm{n}=6)$, miRNA25-3p NC $(10 \mu \mathrm{L}, 100 \mu \mathrm{g} / \mathrm{mL}, \mathrm{N} / \mathrm{P}=8, \mathrm{n}=6)$, and miRNA$25-3 \mathrm{p}$ mimic/MCBC $(10 \mu \mathrm{L}, 100 \mu \mathrm{g} / \mathrm{mL}, \mathrm{N} / \mathrm{P}=8, \mathrm{n}=6)$ 2 weeks post-surgery. Six normal rats served as normal controls ( $\mathrm{n}=6)$. All efforts were made to minimize suffering. All rats were housed under standard diurnal light/dark conditions, fed a standard commercial diet and allowed free access to water. The body weight and tail of each rat were measured and checked once per week to monitor their health status. Eight weeks after injection, a microcomputed tomography (CT) was taken to assess the degree of disc degeneration. All radiograph images were analyzed using ImageJ software (NIH, Bethesda, MD). Disc height index (DHI) was determined as previously described (27). Thereafter, rats were sacrificed and discs were harvested for analysis. Histological hematoxylin-eosin (HE) and safraninO-fast green (SO-FG) staining methods were performed. Histological results for assessing disc degeneration were quantified by histological scores based on the method by Masuda et al. (27).

\section{Statistical analysis}

Data were analyzed using SPSS 20.0 and represented as the mean \pm standard deviation (SD). Analysis of variance (ANOVA) or a Student's $t$-test was performed to measure statistical differences between treatment groups, and $\mathrm{P}<0.05$ was considered statistically significant.

\section{Results}

\section{IL-1 $\beta$, ZIP8 and MTF1 were overexpressed but miRNA- 25-3P was downregulated in degenerated NP tissue}

As shown in Figure 2A, HE staining revealed that NP cells were chondrocyte-like in normal NP tissue and fibrocytelike in degenerated NP tissue. The number of NP cells decreased in degenerated NP tissues. After SO-FG staining, the ECM in normal NP tissue was cartilage-like and stained orange, whereas the ECM in degenerated NP tissue was fibrotic and stained green. Degenerated samples had significantly increased mRNA expression of IL-1 $\beta$, ZIP8 and MTF1 compared with normal samples (Figure 2B). Similarly, protein expression of IL-1 $\beta$, ZIP8 and MTF1 increased in degenerated samples compared with normal samples (Figure 2C). This suggests that activated IL-1 $\beta$, ZIP8, and MTF1 expression is implicated in the IDD process. Consistent with previous studies, the expression level of miRNA-25-3p was verified by qRT-PCR in both degenerated and normal NP tissues. Significantly decreased miRNA-25-3p expression was observed in each degenerated sample compared to normal samples (Figure 2D). This suggests that miRNA-25-3p might be involved in the process of IDD.

\section{$I L-1 \beta$ induced the expression of ZIP8 and nuclear translocation of MTF1}

Total cell proteins and nucleus proteins were isolated separately, and ZIP8 and nuclear MTF1 expression were 
A

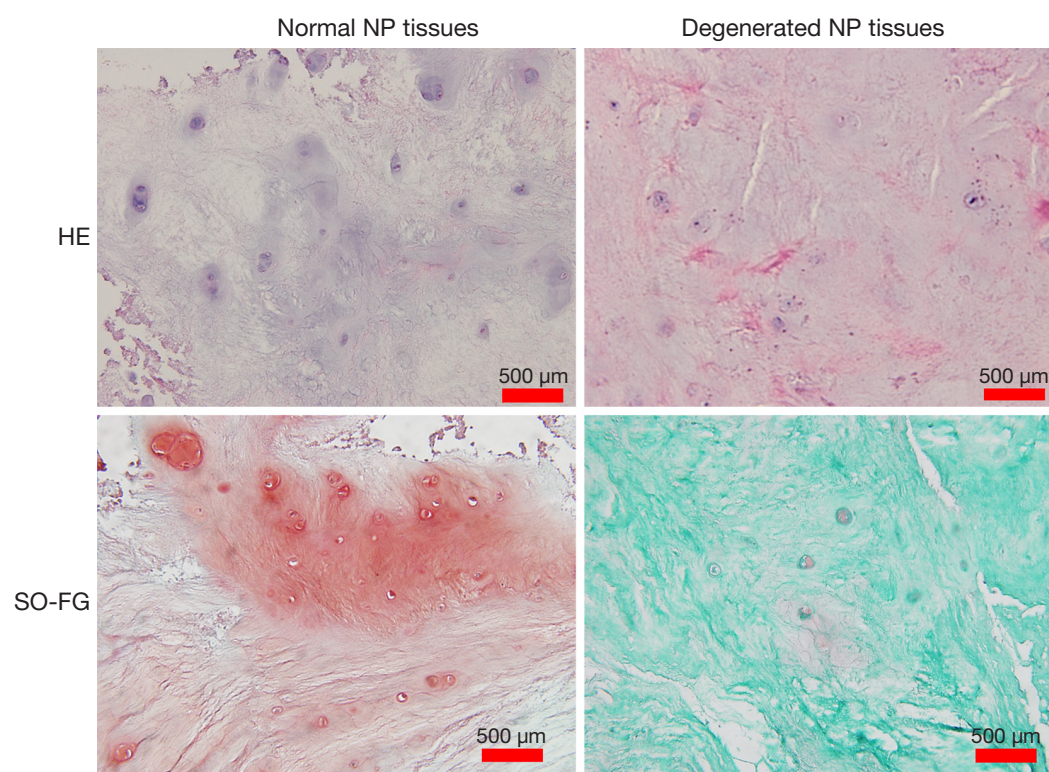

B
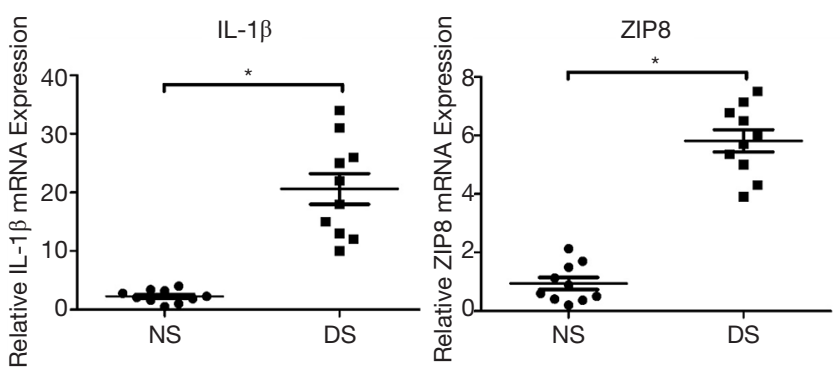

C
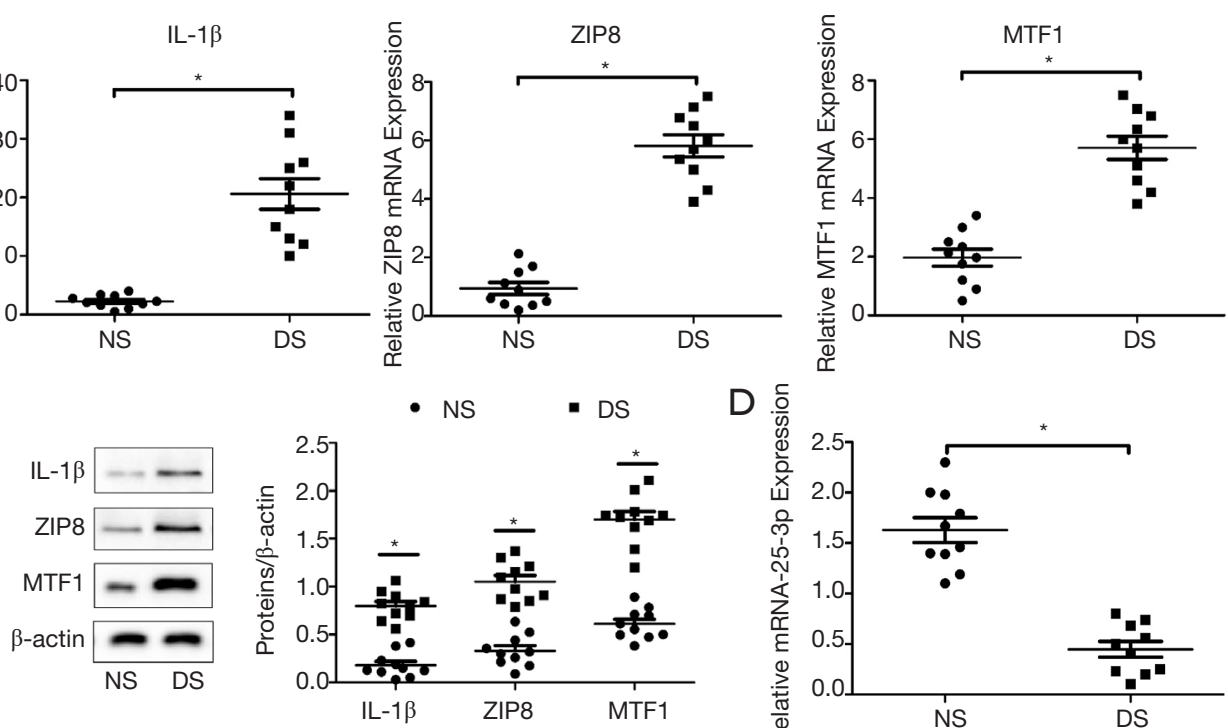

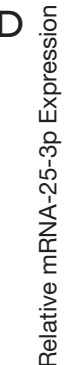

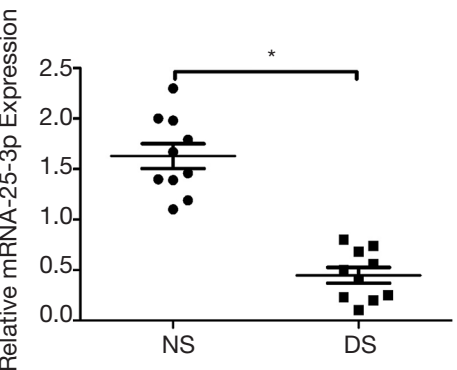

Figure 2 Different expression profiles of IL-1 $\beta$, ZIP8, MTF1 and miRNA-25-3p between normal and degenerated nucleus pulposus (NP) tissue. (A) Representative hematoxylin-eosin (HE) and safranin-O-fast green (SO-FG) staining of normal and degenerated human NP tissue. The bar is $500 \mu \mathrm{m}$. (B) Relative expression levels of IL-1 $\beta$ mRNA, ZIP8 mRNA and MTF1 mRNA were assessed in normal samples (NS) and degenerated samples (DS) of NP tissue ( $n=10)$ via qRT-PCR. (C) Relative expression profiles of IL-1 $\beta$, ZIP8 and MTF1 proteins were examined in normal and degenerated NP tissue $(n=10)$ via western blotting. (D) Expression of miRNA-25-3p in normal and degenerated NP tissue ( $\mathrm{n}=10)$. Symbols represent individual disc samples; bars show the mean and $95 \%$ confidence interval for each group. ${ }^{*}, \mathrm{P}<0.05$.

examined by western blot analysis. As shown in Figure 3, the total expression of ZIP8 (Figure $3 A$ ) and the amount of MTF1 in the nucleus (Figure $3 B$ ) were induced by IL$1 \beta$ treatment. The enhanced expression of ZIP8 and MTF1 were IL- $1 \beta$ dose-dependent. This indicates that IL-1 $\beta$ promotes the expression of ZIP8 in NP cells and subsequently MTF1 nuclear translocation, suggesting that the IL-1 $\beta / Z I P 8 / M T F 1$ signaling pathway plays a role in NP cells.

\section{$I L-1 \beta$ promoted the expression of matrix degrading enzymes and inbibited ECM synthesis}

To observe the effects of the IL- $1 \beta$ signaling pathway, 
A

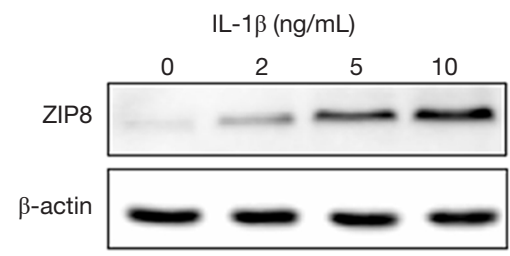

B

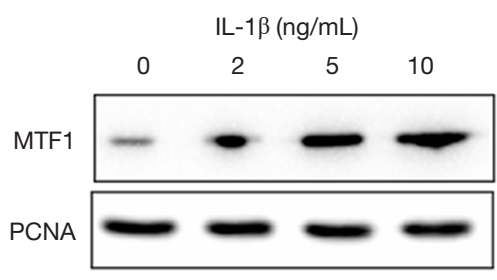

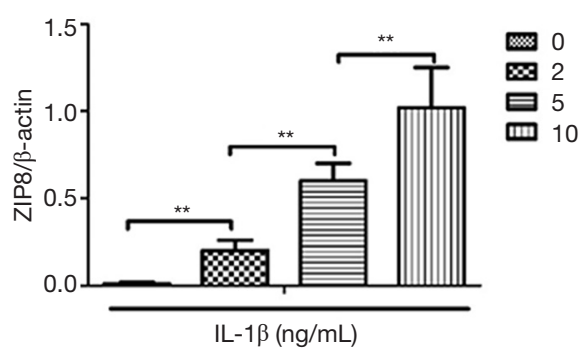

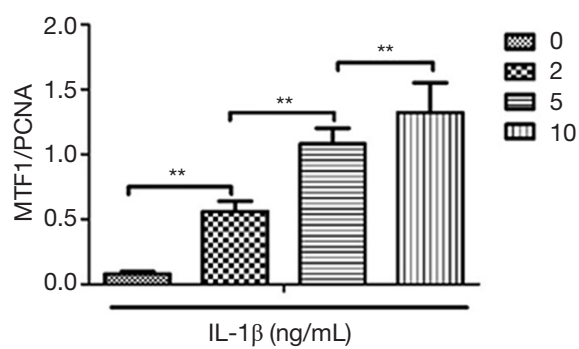

Figure 3 Dose-dependent changes in ZIP8 and MTF1 protein expression after IL-1 $\beta$ stimulation in nucleus pulposus (NP) cells. Human NP cells were cultured for 72 hours in serum with different concentrations of IL-1 $\beta$. (A) ZIP8 protein expression changes with $\beta$-actin normalization. (B) Nuclear MTF1 protein expression changes with PCNA normalization. Data are the mean \pm standard deviation (SD) of triplicate results. ${ }^{* *}, \mathrm{P}<0.01$.

NP cells were stimulated with IL-1 $\beta$ at a concentration of $10 \mathrm{ng} / \mathrm{mL}$. Consequently, the associated ECM-degrading enzymes (MMP3, MMP13 and ADAMTS5) were significantly enhanced in the IL-1 $\beta$ treated group as shown in Figure 4A,B. Moreover, the main components of the ECM (collagen type II and aggrecan) were significantly inhibited (Figure 4C).

\section{Overexpression of miRNA-25-3p reversed the $I L-1 \beta$ - induced downregulation of the ECM by inbibiting the expression of MMP3, MMP13 and ADAMTS5}

NP cells transfected with a miRNA-25-3p mimic inhibited IL-1 $\beta$-induced effects on associated ECM-degrading enzymes (MMP3, MMP13 and ADAMTS5). The mRNA and protein expression of ECM-degrading enzymes decreased in the miRNA-25-3p mimic group (Figure $5 A, B$ ). Subsequently, the expression of the ECM proteins collagen type II and aggrecan recovered (Figure 5C). This suggests that miRNA-25-3p has a protective effect on NP cells while inhibiting the IL- $1 \beta$ signaling pathway.

\section{MTF1 as the target gene of miRNA-25-3p}

According to the target gene prediction by the miRBase database, MTF1 might be a target protein of miRNA- 25-3p. To identify the target of miRNA-25-3p, a dual luciferase assay was implemented. A putative miRNA25-3p seed sequence was expected in the 3 'UTR region of MTF1 (Figure 6A). As shown in Figure 6B, luciferase activity was significantly decreased in NP cells with miRNA-25-3p transfection compared to those treated with the NC, however, mutation of the predicted seed sequence of miRNA-25-3p on MTF1 3'UTR salvaged this effect. To further verify the effects of miRNA-25-3p on MTF1 expression, NP cells were transfected with a miRNA-25-3p mimic and the NC. Compared with the miRNA-25-3p NC, NP cells transfected with the miRNA-25-3p mimic exhibited a decreased expression of MTF1 mRNA (Figure 6C) and protein (Figure 6D). These results demonstrated that miRNA-25-3p precisely regulated the expression of MTF1, thus has a protective effect on NP cells stimulated with IL-1 $\beta$. Overall, IL-1 $\beta$ promoted zinc transporter ZIP8 expression and enhanced MTF1 nuclear translocation. This led to an increased expression of MMP3, MMP13, and ADAMTS5 matrix degrading enzymes and ECM degradation. Therefore, miRNA-25-3p has the potential to silence MTF1 protein expression and have protective effects on IDD (Figure 6E).

\section{MCBC delivered miRNA into NP cells effectively}

As shown in Figure $7 A$, no red fluorescence was observed 
A

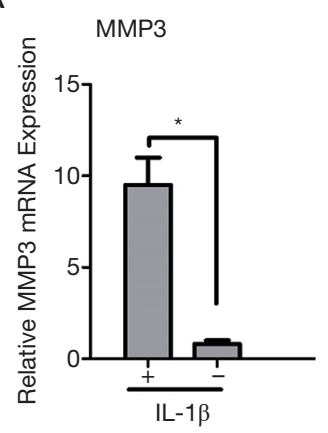

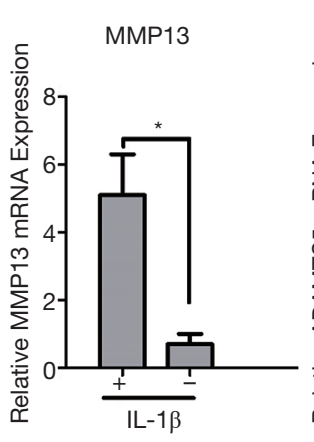

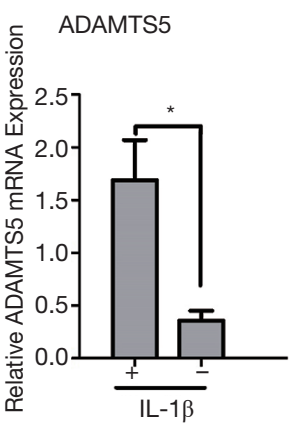

C

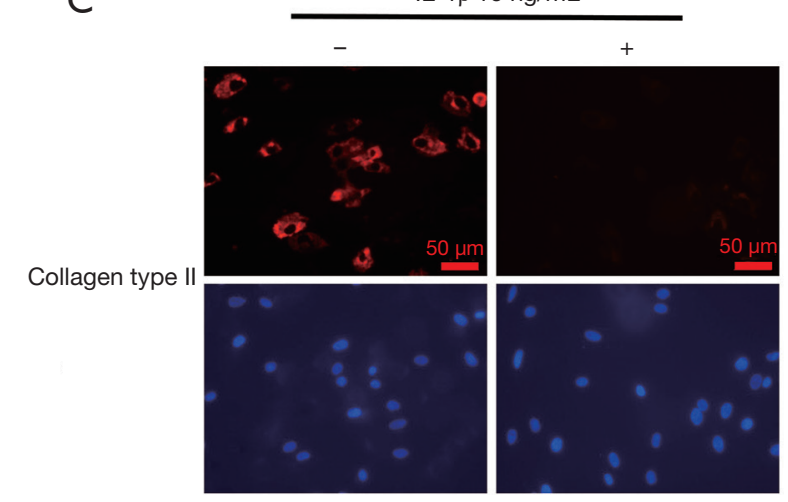

B

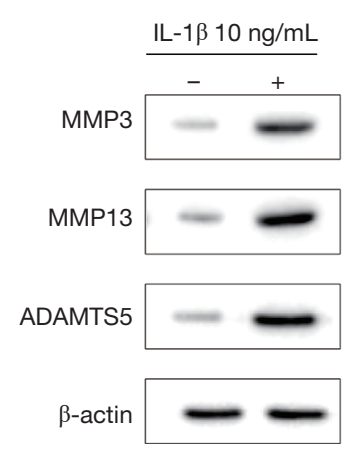

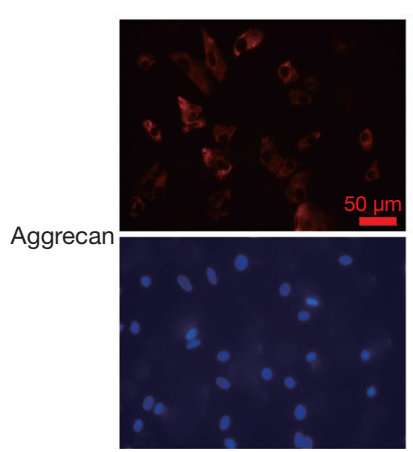

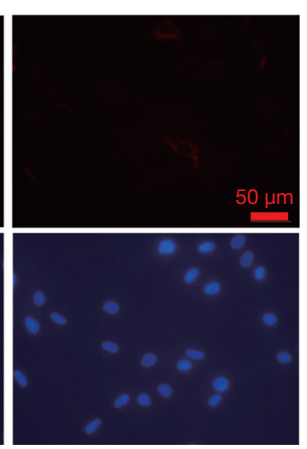

Figure 4 The influence of IL-1 $\beta$ on ECM-degrading enzyme (MMP3, MMP13 and ADAMTS5) and ECM protein (collagen type II and aggrecan) expression. (A) Relative expression levels of MMP3 mRNA, MMP13 mRNA and ADAMTS5 mRNA in IL-1 $\beta$-stimulated nucleus pulposus (NP) cells $(10 \mathrm{ng} / \mathrm{mL})$ and control cells via qRT-PCR. (B) Relative protein expression levels of MMP3, MMP13 and ADAMTS5 were examined in IL-1 $\beta$-stimulated NP cells $(10 \mathrm{ng} / \mathrm{mL})$ and control cells via western blotting. (C) Relative protein expression levels of collagen type II and aggrecan were detected in IL-1 $\beta$-stimulated NP cells $(10 \mathrm{ng} / \mathrm{mL}$ ) and control cells via immunocytochemistry (ICC). The bar is $50 \mu \mathrm{m}$. Data are the mean \pm standard deviation (SD) of triplicate results. *, $\mathrm{P}<0.05$.

in NP cells with pure miRNA-25-3p. Lipo2000 has been proven to be an efficient vector for miRNA delivery. We used it as a control for comparison with MCBC. A strong red fluorescence was found in the cytoplasm of NP cells treated with miRNA-25-3p/lipo2000 and miRNA/ MCBC. Cells positive for red fluorescence (Figure $7 B$ ) and average intensity (Figure $7 C$ ) were further analyzed to quantify transfection efficiency. MCBC resulted in similar positive cell numbers and excellent fluorescence intensity to lipo2000. These results demonstrate that MCBC is an effective miRNA delivery vector.

\section{In vivo delivery of miRNA-25-3p delayed the progression of IDD}

The health status of the animals was good throughout the study. No adverse events were found in all procedures. All rats in each group $(n=6)$ were included in the subsequent analyses. The degree of IDD was evaluated by radiographic and histological analysis. As shown in Figure 8A, the normal control intervertebral discs maintained good intervertebral space height, and the intervertebral disc periphery remained flat and smooth. However, IDD in the sham and NC treatment group was obvious. The height of the intervertebral space decreased significantly and the structure of the intervertebral disc periphery was damaged. The height of the intervertebral space in the miRNA-25$3 \mathrm{p}$ mimic treatment group was significantly better than that in the sham and NC treatment groups, however, the height of the intervertebral space was decreased when compared with that of the control group. Further statistical analysis of disc height index results showed that miRNA-25-3p mimic treatment could better maintain intervertebral height, suggesting mild degeneration $(\mathrm{P}<0.05)$ (Figure 8B).

Thereafter, histological staining (Figure $8 C$ ) was used to observe disc degeneration at the microscopic level. $\mathrm{HE}$ 

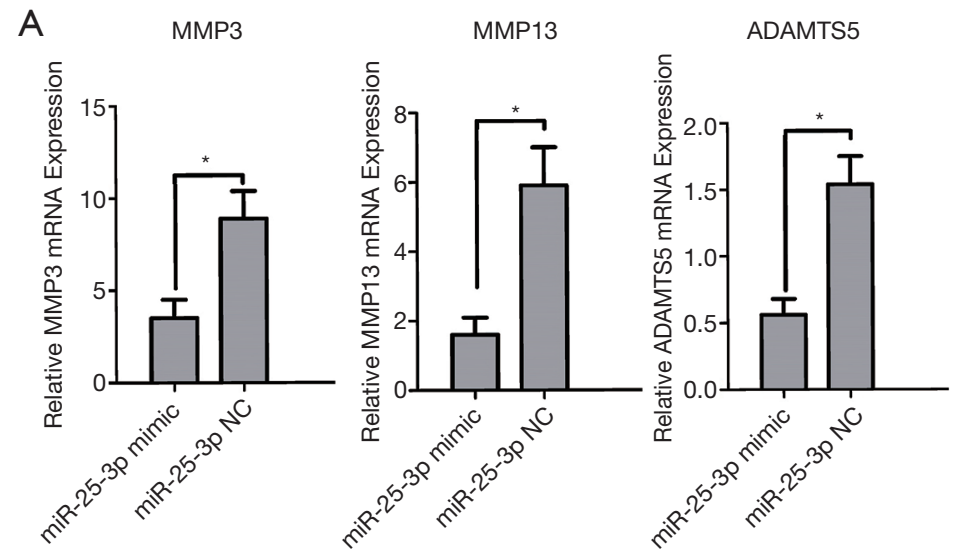

B
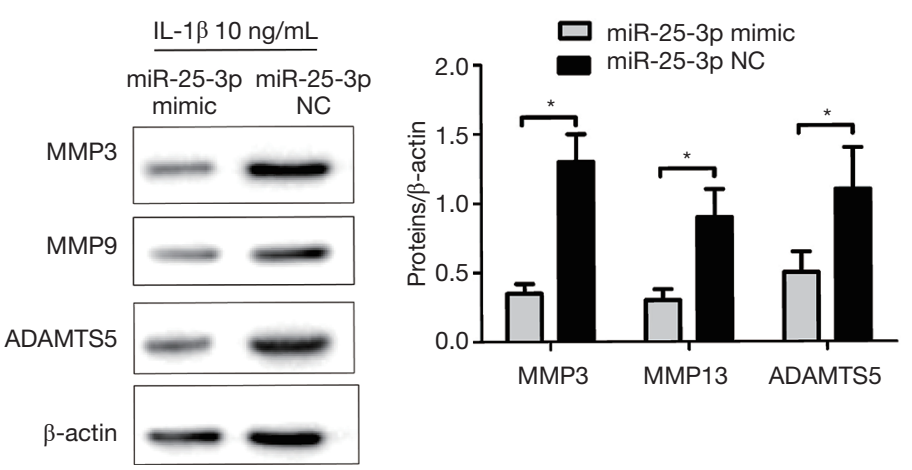

C

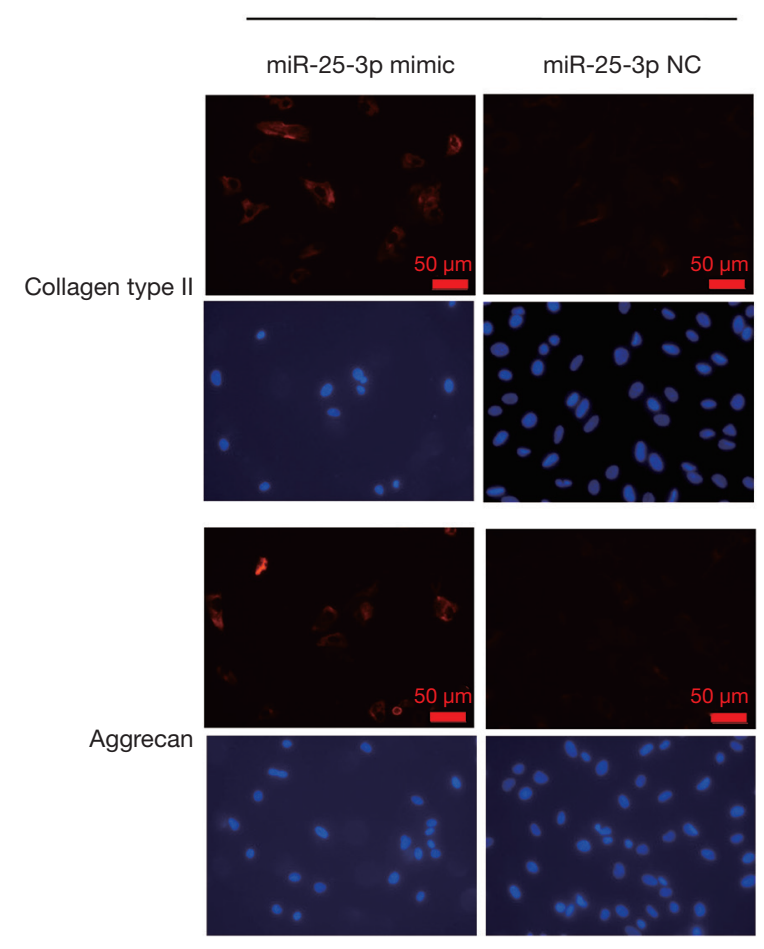

Figure 5 The effects of miRNA-25-3p modulation on IL-1 $\beta$-stimulated ECM-degrading enzyme (MMP3, MMP13 and ADAMTS5) and ECM protein (collagen type II and aggrecan) expression. (A) Relative mRNA expression levels of MMP3, MMP13 and ADAMTS5 in the miRNA-25-3p mimic group and the control group determined via qRT-PCR. (B) Relative protein expression levels of MMP3, MMP13 and ADAMTS5 were examined in the miRNA-25-3p mimic group and the control group via western blotting. (C) Relative protein expression levels of collagen type II and aggrecan were detected in the miRNA-25-3p mimic group and the control group via immunocytochemistry (ICC). The bar is $50 \mu \mathrm{m}$. Data are the mean \pm standard deviation (SD) of triplicate results. *, $\mathrm{P}<0.05$.

staining showed that the degree of IDD in the sham and $\mathrm{NC}$ treatment groups was severe: the basic structure of the NP disappeared, the surrounding area had no clear boundary between the annulus fibrosus and the NP, the NP cells degenerated or disappeared, and rare vacuolated cells were observed. Even though the intact structure of the NP disappeared in the miRNA-25-3p mimic treatment group, some vacuolar cells were still found. These cells adhered to the surrounding annulus fibrosus but had a dividing line, and the degeneration was relatively mild. The control NP cartilage-like ECM was stained orange with SO-FG green staining. Severely degenerated fibrous tissue stained green. In the sham and $\mathrm{NC}$ treatment groups, intervertebral discs were found severely degenerated with a large number of green fibrous tissues. In the miRNA-25-3p mimic treatment group, many orange ECMs were found in the central NP, with a small amount of degenerative fibrous tissue. Here, the degeneration was mild compared to the former groups. A score for every experimental animal in each group was calculated using the histological grading system (Figure 8D). When compared with the sham and NC groups, the miRNA-25 -3p mimic intervention was associated with significantly lower histological grading scores $(\mathrm{P}<0.05)$, suggesting IDD was relatively mild. Overall, this study illustrates the inhibitory effects of miRNA-25-3p on the progression of IDD, thus highlighting its therapeutic value.

\section{Discussion}

Various biological agents, from matrix proteins and recombinant growth factors, to gene-based drugs, have been proposed in preclinical settings for the treatment of 
A

\section{3'-AGUCUGGCUCUGUUCACGUUAC-5' miR-25-3p}

5'-AAAAGCCUGAAAUGUUGCAAUA-3' MTF1 3'-UTR WT

5'-AAAAGCCUGAAAUGUGCAGUCA-3' MTF1 3'-UTR MUT
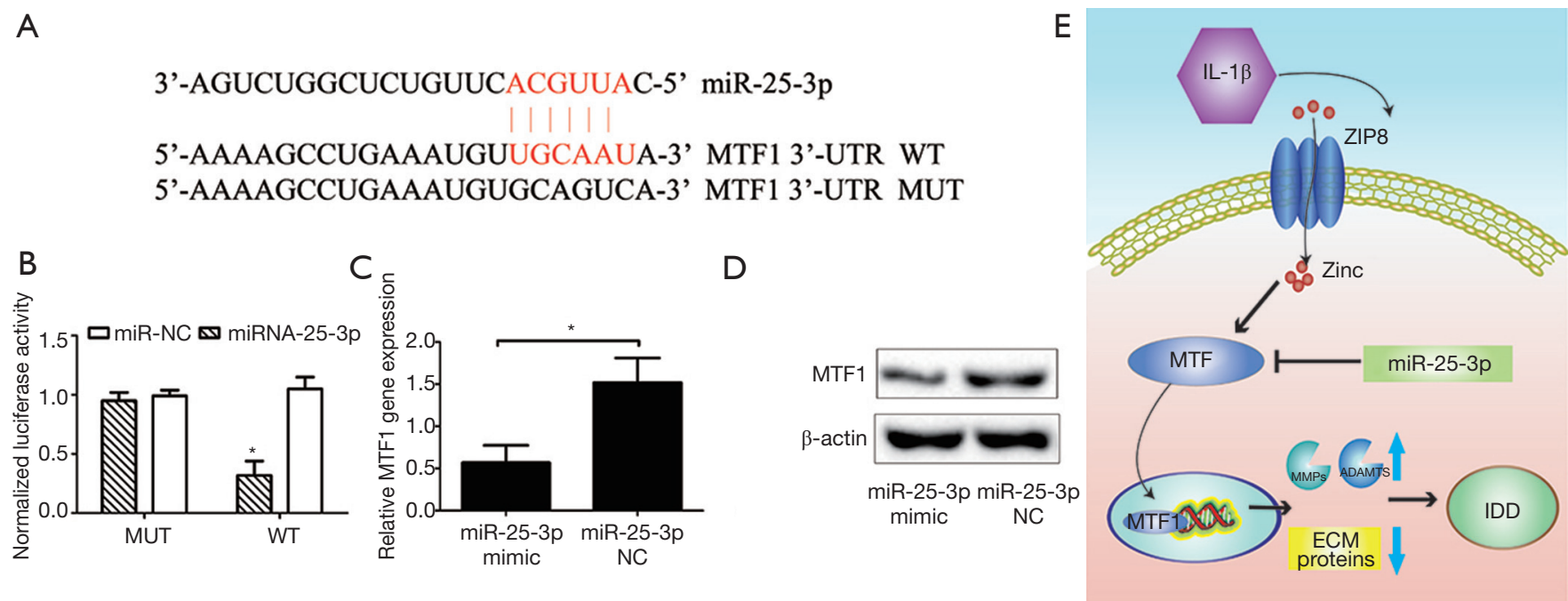

Figure 6 MTF1 is a target gene of miRNA-25-3p. (A) Schematic representation of the MTF 3'UTR showing the putative miRNA target site. (B) Luciferase activity of the MTF1 3'UTR reporter was analyzed in nucleus pulposus (NP) cells. An miRNA-25-3p mimic and its negative control (NC) were co-transfected with the wild-type MTF1 3'UTR or mutant vector. (C) The relative MTF1 mRNA and (D) protein expression of transfected NP cells with the miRNA-25-3p mimic and the NC were assessed using qRT-PCR and western blotting, respectively. $\beta$-actin was used as an internal control. (E) Illustration depicting the IL-1 $\beta / Z$ IP8/MTF1 signaling pathway regulatory mechanisms and miRNA-25-3p targets. Data are represented as the mean \pm standard deviation $(\mathrm{SD}) .{ }^{*}, \mathrm{P}<0.05$.

IDD $(28,29)$. As housekeeping and regulatory non-coding RNAs, miRNAs have shown to be promising agents. For example, a previous animal study demonstrated that miRNA-141 is a key regulator of IDD, and locally delivered miRNA-141 inhibitors mitigated IDD progression (30). Targeting the key molecules that play a central role in IDD is a prerequisite for developing innovative and effective miRNA-based therapies.

Degeneration of the intervertebral disc is accompanied by elevated expression of various inflammatory cytokines. Among them, IL-1 $\beta$ is involved in multiple pathological processes in IDD, such as inflammatory responses, ECM degeneration, angiogenesis and neoinnervation, cell senescence and apoptosis, and oxidative stress $(31,32)$. In recent studies, IL- $1 \beta$ has been shown to facilitate zinc influx by enhancing the zinc transporter ZIP8 expression in chondrocytes $(33,34)$. The expression of ZIP8 also increases, responding to IL-1 $\beta$ treatment to mediate zinc influx in rat NP cells (35). MTF1, a critical transcription factor, is associated with cell adaptation to various environmental stresses, including increased intracellular zinc concentration $(36,37)$. When responding to IL-1 $\beta$-induced zinc influx, MTF1 translocates into the nucleus and induces targeted ECM-degrading enzyme gene expression, including MMP3, MMP13, ADAMTS5 (33,34). In osteoarthritis, the activated IL-1 $\beta / Z I P 8 / M T F 1$ signaling pathway promotes ECM-degrading enzyme expression and aggregates the cartilage destruction (13). The IL-1ß/ZIP8/MTF1 signaling pathway is also involved in the development of IDD as observed in our study. IL- $1 \beta$ was demonstrated to promote ZIP8 expression and MTF1 nuclear translocation in a dosedependent manner in NP cells. Moreover, IL-1 $\beta$ promoted the expression of MTF1 targeted ECM-degrading enzymes MMP3, MMP13, and ADAMTS5, and inhibited the expression of ECM proteins.

ECM-degrading enzymes, such as MMPs and ADAMTSs, play an important role in the repair and remodeling of intervertebral discs. The expression of MMPs and ADAMTSs in degenerative disc tissue can significantly increase and become damaging (38). Immunohistochemical staining in disc tissue has revealed that the greater the expression of MMP3, the greater the severity of disc degeneration (39). In patients with recurrent lumbar disc herniation, a higher expression of MMP3 is seen compared to patients with primary herniation (40). Similarly, MMP13 is highly expressed in degenerative disc tissue and promotes the progression of IDD (41). In addition, increased expression of ADAMTS5 in degenerative discs has been observed, and is associated with modic changes $(42,43)$. Therefore, high expression levels of MMP3, MMP13, and 
A
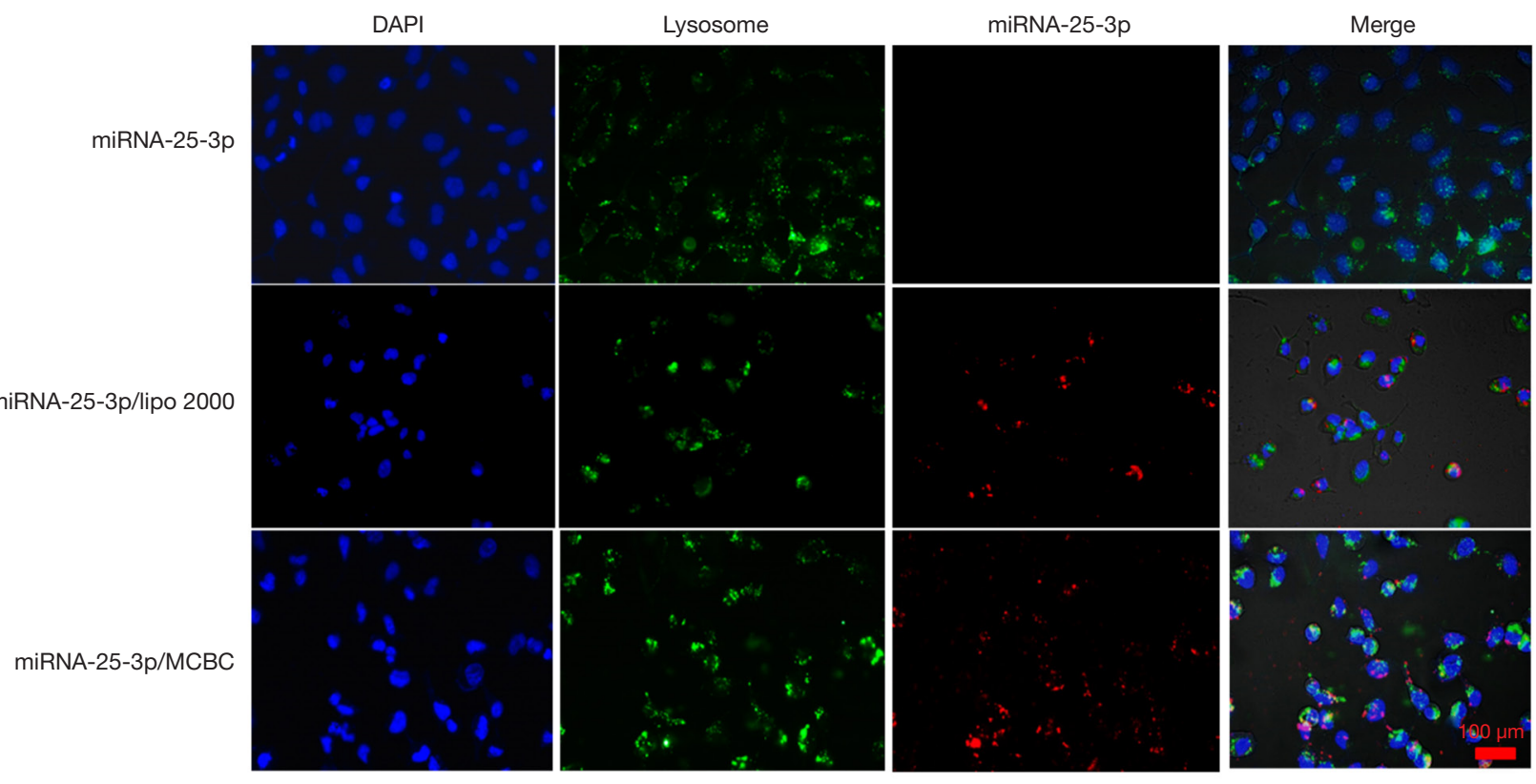

B

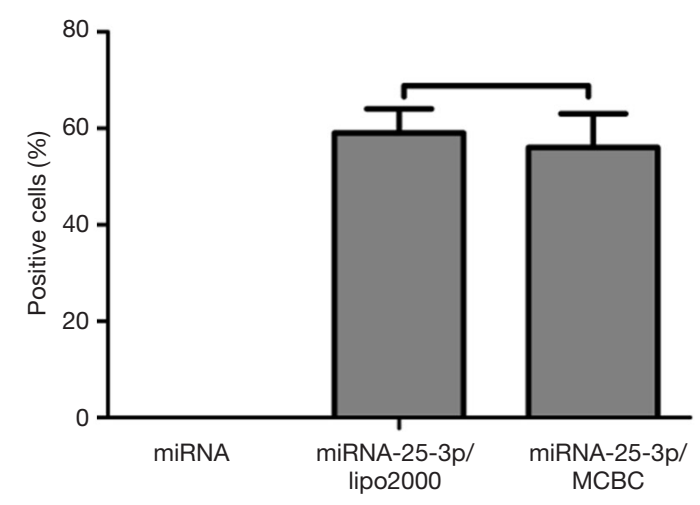

C

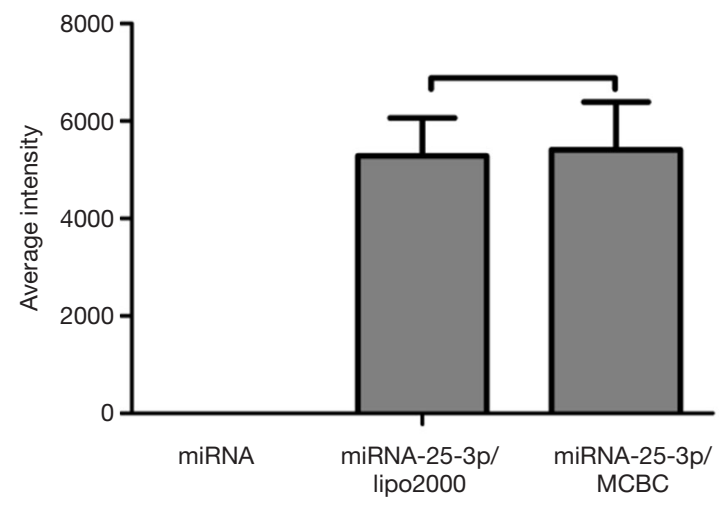

Figure 7 In vitro transfection efficiency of miRNA via mixed cationic block copolymers (MCBC). (A) Fluorescence microscopy images of transfected nucleus pulposus (NP) cells 24 hours after transfection. Scale bar represents $100 \mu \mathrm{m}$. (B) Quantification of cy3-labeled miRNA positive cells. Mean \pm standard deviation (SD), $n=4$. (C) Quantification of fluorescence intensity. Mean $\pm S D, n=4$. No statistical significance was found for transfection efficiency between MCBC and lipo2000.

ADAMTS5 induced by IL- $1 \beta$ act as pathogenic factors to exacerbate the process of IDD. Targeted blocking of this effect may therefore alleviate disc degeneration and facilitate disc repair.

Previous studies have shown that miRNA-25-3p has significant implications in a wide range of diseases, including malignant tumors, pediatric multiple sclerosis and psychological stress (44-46). However, until now, the role of miRNA-25-3p in IDD had not been studied. As seen in our results, the expression of miRNA-25-3p was significantly decreased in degenerated tissue compared with normal tissue. In vitro studies showed that it inhibited IL-1 $\beta$ - induced expression of the ECM-degrading enzymes MMP3, MMP13, and ADAMTS5, and reversed ECM protein expression. MiRNA-25-3p silenced targeted MTF1 protein expression and inhibited the effects of the IL-1 $\beta / Z I P 8 /$ MTF1 signaling pathway in NP cells. Hence, miRNA-25$3 p$ has a protective effect on IDD and is a promising agent for miRNA-based therapy in IDD.

Animal studies were implemented to examine the effects of miRNA-25-3p on IDD. The cationic polymerbased gene delivery system MCBC was selected as the miRNA-25-3p mimic vector. Degradable cationic polymer PAsp(DET) has a high in vitro gene transfection efficiency 
A

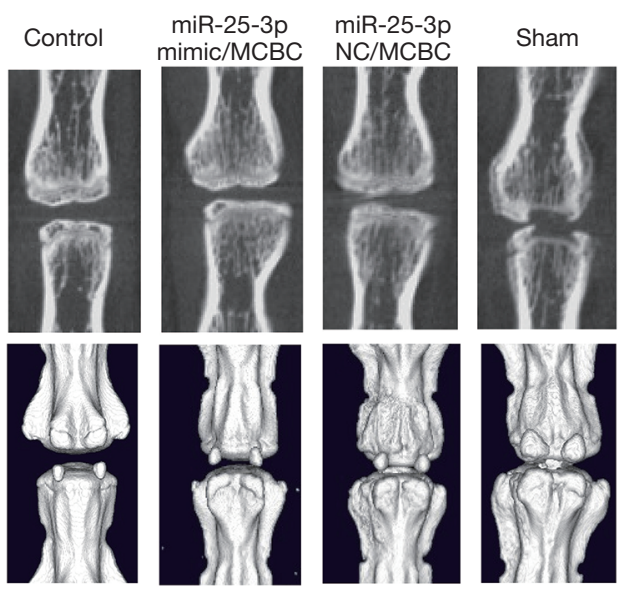

B

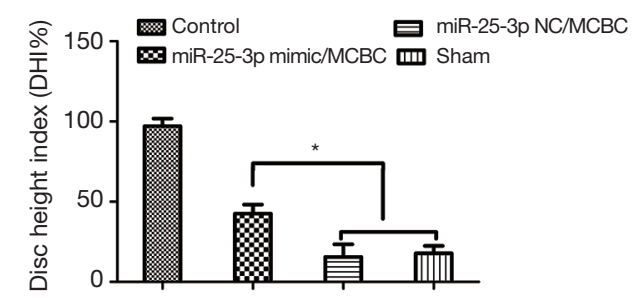

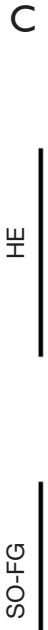
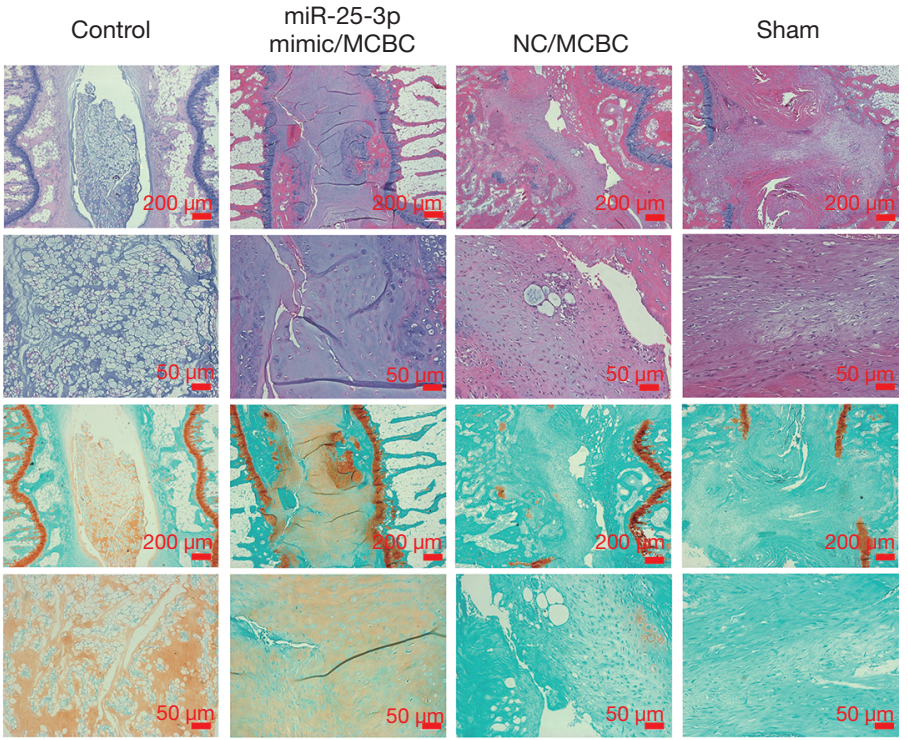

D

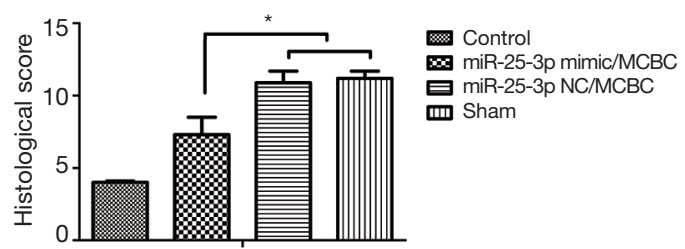

Figure 8 Radiographic and histological data of intervertebral disc degeneration (IDD) in different treatment groups: normal control (NC), miRNA-25-3p mimic treatment group, miRNA-25-3p NC treatment group and sham treatment group. (A) Disc degeneration evaluated by micro-computed tomography (CT) images 8 weeks post-injection of various miRNA formulations. (B) Quantitative results of disc height [presented as the \% disc height index (DHI)]. (C) Histological appearance of disc samples after treatment with different miRNA formulations 4 weeks post-injection. The disc space and nucleus pulposus (NP) area of cross sections were visualized by hematoxylin-eosin (HE) and safranin-O-fast green (SO-FG) staining, respectively. The bar is $200 \mu \mathrm{m}$ (upper) and $50 \mu \mathrm{m}$ (under). (D) Quantitative results of histological scores. Data are represented as the mean \pm standard deviation $(\mathrm{SD}), \mathrm{n}=6 .{ }^{*}, \mathrm{P}<0.05$.

with negligible toxicity (47). PAsp(DET) can be easily absorbed by charged components and be rapidly cleared under physiological conditions in vivo. In order to improve the PAsp(DET) stability in vivo, surface modification with PEG was developed to form the block copolymer PEG-bPAsp(DET) (48). However, the dense PEG shell decreases transfection efficiency because it reduces the affinity between the cationic polymer and the cell membrane. To further develop vectors with high stability and transfection efficiency to achieve optimal therapeutic potency, a thermoresponsive vector $\mathrm{MCBC}$ was developed by complexation between PNIPAM-b-PAsp(DET) and PEG-b-PAsp(DET). PNIPAM-b-PAsp(DET) makes MCBC present with heterogeneous surfaces by changing the temperature from 25 to $37^{\circ} \mathrm{C}$ (22). At $37^{\circ} \mathrm{C}$, a hydrophobic PNIPAM core was formed in the micellar architecture from PNIPAMb-PAsp(DET), which facilitates gene transfection.
Alternatively, heterogeneous hydrophobic/hydrophilic surfaces further improved gene condensation and stability $(49,50)$. Accordingly, high efficiency of in vitro miRNA transfection by the thermo-responsive vector MCBC was observed in our study. From the histological examination, it can be seen that miRNA-25-3p effectively delivered by MCBC maintained intervertebral disc height via micro-CT analysis and delayed the progression of IDD. This suggests that MCBC-mediated miRNA-25-3p for IDD treatment is viable and effective in a rat model, and provides strong evidence for the potential clinical application of miRNA25-3p-based therapy to treat IDD patients.

From our results, some significant benefits were obtained from miRNA-25-3p treatment, notably, sustaining disc height, restoring ECM proteins in NP cells, and maintaining structural integrity of the disc. Unfortunately, the degenerated disc did not completely 
recover. One possible reason is that the degenerated disc microenvironment is complicated and involves multiple inflammatory cytokines, and miRNA-25-3p is unable to single-handedly mediate these inflammatory processes. More attention should be paid to the discovery of key molecules that are centrally involved in multiple regulatory mechanisms. Furthermore, miRNAs with greater specificity to IDD should also be investigated and applied to improve therapeutic effects in future studies. Although the rat model used in our study can be easily established and has high reproducibility, the rat caudal discs are different from that of humans in terms of mechanical loading, as well as the anatomy and composition of discs. Thus, large animal studies, closer to the size of humans, are needed to verify treatment effects in future studies (51).

In summary, the IL-1 $\beta / Z I P 8 / M T F 1$ signaling pathway is an underlying regulatory mechanism of IDD progression. MiRNA-25-3p can precisely silence the targeted MTF1 protein expression and inhibit IL-1 $\beta$-induced effects. The thermo-responsive vector delivering miRNA-25-3p delayed the progression of IDD in vivo, and is therefore a potential therapeutic approach for IDD in the future.

\section{Acknowledgments}

We would like to acknowledge the National Natural Science Foundation of China for supporting and funding this work. We would also like to thank all the patients who donated their nucleus pulposus tissues.

Funding: The authors gratefully acknowledge financial support from the National Natural Science Foundation of China (NSFC) Project $(81572160,81772397,81871772)$.

\section{Footnote}

Reporting Checklist: The authors have completed the ARRIVE reporting checklist. Available at http://dx.doi. org/10.21037/atm-20-6595

Data Sharing Statement: Available at http://dx.doi. org/10.21037/atm-20-6595

Conflicts of Interest: All authors have completed the ICMJE uniform disclosure form (available at http://dx.doi. org/10.21037/atm-20-6595). The authors have no conflicts of interest to declare.

Ethical Statement: The authors are accountable for all aspects of the work in ensuring that questions related to the accuracy or integrity of any part of the work are appropriately investigated and resolved. All procedures performed in this study involving human participants were in accordance with the Declaration of Helsinki (as revised in 2013). Study procedures was approved by the Ethics Review Board of West China Hospital, Sichuan University and written informed consent was obtained from all patients. Animal experiments were performed according to the Guidelines for Animal Experimentation of Sichuan University, and with approval from the Institutional Ethics Committee of West China Hospital, Sichuan University.

Open Access Statement: This is an Open Access article distributed in accordance with the Creative Commons Attribution-NonCommercial-NoDerivs 4.0 International License (CC BY-NC-ND 4.0), which permits the noncommercial replication and distribution of the article with the strict proviso that no changes or edits are made and the original work is properly cited (including links to both the formal publication through the relevant DOI and the license). See: https://creativecommons.org/licenses/by-nc-nd/4.0/.

\section{References}

1. GBD 2016 Disease and Injury Incidence and Prevalence Collaborators. Global, regional, and national incidence, prevalence, and years lived with disability for 328 diseases and injuries for 195 countries, 1990-2016: a systematic analysis for the Global Burden of Disease Study 2016. Lancet 2017;390:1211-59.

2. Argyriou AA, Anastopoulou GG, Bruna J. Inconclusive evidence to support the use of minimally-invasive radiofrequency denervation against chronic low back pain. Ann Transl Med 2018;6:127.

3. Atlas SJ. Point of View: Avoiding Opioids in Patients With Work-related Lumbar Disc Herniation. Spine (Phila Pa 1976) 2018;43:603-4.

4. Sakai D, Grad S. Advancing the cellular and molecular therapy for intervertebral disc disease. Adv Drug Deliv Rev 2015;84:159-71.

5. Vergroesen PP, Kingma I, Emanuel KS, et al. Mechanics and biology in intervertebral disc degeneration: a vicious circle. Osteoarthritis Cartilage 2015;23:1057-70.

6. Dowdell J, Erwin M, Choma T, et al. Intervertebral Disk Degeneration and Repair. Neurosurgery 2017;80:S46-54.

7. Risbud MV, Shapiro IM. Role of cytokines in intervertebral disc degeneration: pain and disc content. 
Nat Rev Rheumatol 2014;10:44-56.

8. Johnson ZI, Schoepflin ZR, Choi H, et al. Disc in flames: Roles of TNF-alpha and IL-1beta in intervertebral disc degeneration. Eur Cell Mater 2015;30:104-16; discussion 116-7.

9. Le Maitre CL, Freemont AJ, Hoyland JA. The role of interleukin-1 in the pathogenesis of human intervertebral disc degeneration. Arthritis Res Ther 2005;7:R732-45.

10. Wang WJ, Yu XH, Wang C, et al. MMPs and ADAMTSs in intervertebral disc degeneration. Clin Chim Acta 2015;448:238-46.

11. Page-McCaw A, Ewald AJ, Werb Z. Matrix metalloproteinases and the regulation of tissue remodelling. Nat Rev Mol Cell Biol 2007;8:221-33.

12. Prasad AS. Zinc: an overview. Nutrition 1995;11:93-9.

13. Kim JH, Jeon J, Shin M, et al. Regulation of the catabolic cascade in osteoarthritis by the zinc-ZIP8-MTF1 axis. Cell 2014;156:730-43.

14. Amin NP, Mohindra P, Jabbour SK. Serum microRNA guiding personalized radiation therapy in non-small cell lung cancer. J Thorac Dis 2018;10:S4108-12.

15. Wang C, Wang WJ, Yan YG, et al. MicroRNAs: New players in intervertebral disc degeneration. Clin Chim Acta 2015;450:333-41.

16. Lin X, Lin Q. MiRNA-495-3p Attenuates TNF-alpha Induced Apoptosis and Inflammation in Human Nucleus Pulposus Cells by Targeting IL5RA. Inflammation 2020;43:1797-805.

17. Zhao B, Yu Q, Li H, et al. Characterization of microRNA expression profiles in patients with intervertebral disc degeneration. Int J Mol Med 2014;33:43-50.

18. Li Z, Rana TM. Therapeutic targeting of microRNAs: current status and future challenges. Nat Rev Drug Discov 2014;13:622-38.

19. Si HB, Zeng Y, Liu SY, et al. Intra-articular injection of microRNA-140 (miRNA-140) alleviates osteoarthritis (OA) progression by modulating extracellular matrix (ECM) homeostasis in rats. Osteoarthritis Cartilage 2017;25:1698-707.

20. Yin H, Kanasty RL, Eltoukhy AA, et al. Non-viral vectors for gene-based therapy. Nat Rev Genet 2014;15:541-55.

21. Li Y, Li J, Chen B, et al. Polyplex micelles with thermoresponsive heterogeneous coronas for prolonged blood retention and promoted gene transfection. Biomacromolecules 2014;15:2914-23.

22. Feng G, Chen H, Li J, et al. Gene therapy for nucleus pulposus regeneration by heme oxygenase- 1 plasmid DNA carried by mixed polyplex micelles with thermo-responsive heterogeneous coronas. Biomaterials 2015;52:1-13.

23. Alini M, Eisenstein SM, Ito K, et al. Are animal models useful for studying human disc disorders/degeneration? Eur Spine J 2008;17:2-19.

24. Pfirrmann CW, Metzdorf A, Zanetti M, et al. Magnetic resonance classification of lumbar intervertebral disc degeneration. Spine (Phila Pa 1976) 2001;26:1873-8.

25. Penolazzi L, Lambertini E, Bergamin LS, et al. MicroRNA-221 silencing attenuates the degenerated phenotype of intervertebral disc cells. Aging (Albany NY) 2018;10:2001-15.

26. Jiang LB, Cao L, Ma YQ, et al. TIGAR mediates the inhibitory role of hypoxia on ROS production and apoptosis in rat nucleus pulposus cells. Osteoarthritis Cartilage 2018;26:138-48.

27. Masuda K, Aota Y, Muehleman C, et al. A novel rabbit model of mild, reproducible disc degeneration by an anulus needle puncture: correlation between the degree of disc injury and radiological and histological appearances of disc degeneration. Spine (Phila Pa 1976) 2005;30:5-14.

28. Chen S, Liu S, Ma K, et al. TGF-beta signaling in intervertebral disc health and disease. Osteoarthritis Cartilage 2019;27:1109-17.

29. Priyadarshani P, Li Y, Yao L. Advances in biological therapy for nucleus pulposus regeneration. Osteoarthritis Cartilage 2016;24:206-12.

30. Ji ML, Jiang $\mathrm{H}$, Zhang $\mathrm{XJ}$, et al. Preclinical development of a microRNA-based therapy for intervertebral disc degeneration. Nat Commun 2018;9:5051.

31. Yang $\mathrm{W}$, Yu XH, Wang C, et al. Interleukin-1beta in intervertebral disk degeneration. Clin Chim Acta 2015;450:262-72.

32. Jin $\mathrm{H}$, Wang $\mathrm{Q}$, Wu J, et al. Baicalein Inhibits the IL1beta-Induced Inflammatory Response in Nucleus Pulposus Cells and Attenuates Disc Degeneration In vivo. Inflammation 2019;42:1032-44.

33. Lee $M$, Won $Y$, Shin $Y$, et al. Reciprocal activation of hypoxia-inducible factor (HIF)-2alpha and the zinc-ZIP8MTF1 axis amplifies catabolic signaling in osteoarthritis. Osteoarthritis Cartilage 2016;24:134-45.

34. Song J, Kim D, Lee CH, et al. MicroRNA-488 regulates zinc transporter SLC39A8/ZIP8 during pathogenesis of osteoarthritis. J Biomed Sci 2013;20:31.

35. Yin XF, Jiang LB, Ma YQ, et al. Decreased Zn(2+) Influx Underlies the Protective Role of Hypoxia in Rat Nucleus Pulposus Cells. Biol Trace Elem Res 2015;168:196-205.

36. Laity JH, Andrews GK. Understanding the mechanisms of zinc-sensing by metal-response element binding 
transcription factor-1 (MTF-1). Arch Biochem Biophys 2007;463:201-10.

37. Colvin RA, Holmes WR, Fontaine CP, Maret W. Cytosolic zinc buffering and muffling: their role in intracellular zinc homeostasis. Metallomics 2010;2:306-17.

38. Yao Z, Nie L, Zhao Y, et al. Salubrinal Suppresses IL17-Induced Upregulation of MMP-13 and Extracellular Matrix Degradation Through the NF-kB Pathway in Human Nucleus Pulposus Cells. Inflammation 2016;39:1997-2007.

39. Le Maitre CL, Freemont AJ, Hoyland JA. Localization of degradative enzymes and their inhibitors in the degenerate human intervertebral disc. J Pathol 2004;204:47-54.

40. Ozkanli S, Kaner T, Efendioglu M, et al. The relation of matrix metalloproteinase 1, 2, 3 expressions with clinical and radiological findings in primary and recurrent lumbar disc herniations. Turk Neurosurg 2015;25:111-6.

41. Li HR, Cui Q, Dong ZY, et al. Downregulation of miR$27 \mathrm{~b}$ is Involved in Loss of Type II Collagen by Directly Targeting Matrix Metalloproteinase 13 (MMP13) in Human Intervertebral Disc Degeneration. Spine (Phila Pa 1976) 2016;41:E116-23.

42. Pockert AJ, Richardson SM, Le Maitre CL, et al. Modified expression of the ADAMTS enzymes and tissue inhibitor of metalloproteinases 3 during human intervertebral disc degeneration. Arthritis Rheum 2009;60:482-91.

43. Chen S, Huang Y, Zhou ZJ, et al. Upregulation of tumor necrosis factor alpha and ADAMTS-5, but not ADAMTS-4, in human intervertebral cartilage endplate with modic changes. Spine (Phila Pa 1976) 2014;39:E817-25.

44. Pfau ML, Menard C, Cathomas F, et al. Role of Monocyte-Derived MicroRNA106b approximately

Cite this article as: Huang Y, Huang L, Li L, Ge Z, Feng G, Liu L, Song Y. MicroRNA-25-3p therapy for intervertebral disc degeneration by targeting the IL-1 $/$ /ZIP8/MTF1 signaling pathway with a novel thermo-responsive vector. Ann Transl Med 2020;8(22):1500. doi: 10.21037/atm-20-6595
25 in Resilience to Social Stress. Biol Psychiatry 2019;86:474-82.

45. Zhang J, Bai R, Li M, et al. Excessive miR-25-3p maturation via $\mathrm{N}(6)$-methyladenosine stimulated by cigarette smoke promotes pancreatic cancer progression. Nat Commun 2019;10:1858.

46. Liguori M, Nuzziello N, Licciulli F, et al. Combined microRNA and mRNA expression analysis in pediatric multiple sclerosis:an integrated approach to uncover novel pathogenic mechanisms of the disease. Hum Mol Genet 2018;27:66-79.

47. Miyata K, Oba M, Nakanishi M, et al. Polyplexes from poly(aspartamide) bearing 1,2-diaminoethane side chains induce $\mathrm{pH}$-selective, endosomal membrane destabilization with amplified transfection and negligible cytotoxicity. J Am Chem Soc 2008;130:16287-94.

48. Oba M, Miyata K, Osada K, et al. Polyplex micelles prepared from omega-cholesteryl PEG-polycation block copolymers for systemic gene delivery. Biomaterials 2011;32:652-63.

49. Calejo MT, Cardoso AM, Kjoniksen AL, et al. Temperature-responsive cationic block copolymers as nanocarriers for gene delivery. Int J Pharm 2013;448:105-14.

50. Wong SY, Han L, Timachova K, et al. Drastically lowered protein adsorption on microbicidal hydrophobic/hydrophilic polyelectrolyte multilayers. Biomacromolecules 2012;13:719-26.

51. Gullbrand SE, Malhotra NR, Schaer TP, et al. A large animal model that recapitulates the spectrum of human intervertebral disc degeneration. Osteoarthritis Cartilage 2017;25:146-56. 